\title{
Color Emotional Expression in Cultural and Creative Product Design
}

\author{
Wang $\mathrm{Fa}^{1,2}$ \\ 1. Jiangsu Vocational Institute of Architectural Technology \\ Xuzhou, China \\ ${ }^{2}$.Department of Industrial Design \\ Pukyong National University \\ Busan, Korea
}

\author{
Cho Joung Hyung* \\ Department of Industrial Design \\ Pukyong National University \\ Busan, Korea
}

\begin{abstract}
This paper studies how people-oriented color design concepts express emotion in design, analyzes the influence of color in visual language on the consumer behavior in the emotional expression of cultural and creative products starting from the humanistic concern and emotional expression, assists designers to more accurately give expression to products, evokes consumer emotions, captures the target market and satisfies the consumer's aesthetic and spiritual life needs to design a product that has cultural connotation, appeal, and can satisfy people's emotional experience needs.
\end{abstract}

Keywords-cultural and creative products, color performance, emotional design, visual symbols

\section{INTRODUCTION}

With the rapid development of social economy, current cultural and creative product design field has attracted people's great attention. To avoid product homogeneity, cultural and creative products must be designed with personalized and symbolized properties. Color is an important element constituting a design expression language in cultural and creative product design. Individual expression of color language can meet people's need for daily aesthetics. The visual novelty and symbolism that color possesses can inspire people's desire to purchase desire for cultural and creative products. Reasonable color combination can scientifically induce people's emotions in boldness, quietness, gracefulness, or bitterness, all of which are the soul concepts conveyed to the viewers in visual language. Therefore, analysis and exploration of the color emotional expression in the field of cultural and creative product design from the perspective of color science can not only promote the formation of unique emotional symbols for cultural and creative products, but also enhance promote the interdisciplinary integration and integration of cultural and creative products. Simutaneously, it can use promote the interdisciplinary integration and integration of cultural and creative products design and also nurture the industry to improve its artistry.

\section{SIGNIFICANCE OF EMOTIONAL EXPRESSION IN CULTURAL AND CREATIVE PRODUCT DESIGN}

Emotion as a psychological noun refers to people's attitude towards the surroundings, self, and their own behavior. It is a unique form of reflection of objective things, and also an externalized form of whether the object meets the needs of the subject. Emotions in cultural and creative products are the feelings produced by consumers' physiological and psychological needs in the process of their usage due to the harmonious coexistence of people and products. The emotional manifestation of cultural and creative products is different from simple information transmission. The emotional expression of products is the transformation of high-level visual information symbols established by designers through the medium of products. In addition, emotional expression is a complicated encoding process which can promote the human interest of products, cater to consumers' emotional needs, and follow the rules of human emotions and activities. "People are touched firstly by emotions". So the emotional intervention in cultural and creative products based on consumers' emotional demand as the principle can promote products to present its diversity and personalized features.

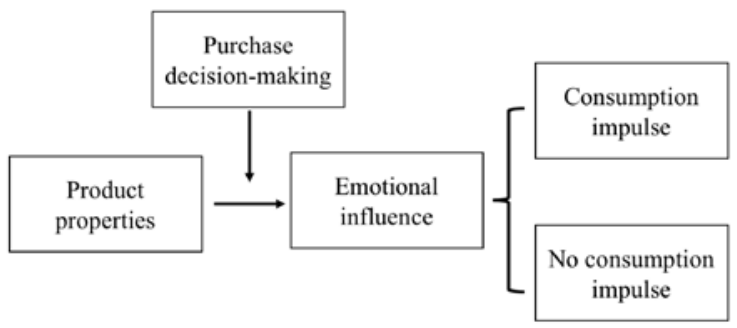

Fig. 1. Emotional design can influence consumption

The color element of a product's appearance expression can better attract consumers' emotional needs. Therefore, researching the emotional expression of product color is an effective way to explore the development rules, consumers' demands, and emotional charm of cultural and creative products. "When people perceive colors through their visual organs, they are often accompanied by other sensory organs and brain activities, and produce comprehensive awareness and awareness activities." Color psychology is the subjective psychological reaction caused by the objective world, in fact, it is the mental activity produced by light acting on human visual organs. Color feedback includes other senses such as hearing, taste, touch and smell. After a long period of social development, people also summarized different colors with 
different understandings, which also produced different emotional resonance. Cultural and creative products have different emotional interactions based on people's understanding of different colors. And these different kinds of feedback are the basic way of color emotional expression of products.

John Nesbitt believes that: "There needs to be a high emotional level of compensation everywhere. The more high technology we have in our society, the more we want to create a highly emotional environment and adopt the soft side of technology to balance its hard side." 'We must learn to balance the material wonders of technology with the spirit of human nature" so as to realize the transform from "obsessive technique to a balance between high technology and high emotional states."

In the design and application of the color of cultural creative products, the expression of color intention (including the expressive force of color itself, the symbolic color, the color association and the emotion of color) is emphasized and deepened, which is especially important for the whole design. "Image can be understood in color design as a reflection of color itself. At the same time, it can evoke a certain kind of appearance or sensation. It can reach people' s hearts, enrich deep aesthetic tastes, and satisfy the product' s desired image in people' $s$ minds. Different living environments, experiences, and other influences make them be filled with different aesthetics, and the color images produced by the products will not be exactly the same." Creative product color design makes people have more space to associate. "Color association is a kind of extension of human's second signal system to color perception, which is based on human direct and indirect experience." Therefore, to arouse the audience's good association and emotional resonance to life, we could successfully promote the formation of good images to give the product soul and vitality. However, the emotional symbol of color, on the basis of association and emotional resonance, makes the color itself add the content of its emotional expression. These deep product colors affect human beings, and its content expressed is very important in the color design of cultural and creative products.

\section{HUMANISTIC CONCERN OF COLORS IN CULTURAL AND CREATIVE PRODUCT DESIGN}

In modern design ideological trend, modern product design has established a human-oriented design concept. Exquisitelydesigned cultural and creative products must be designed with humanistic concern. Despite colors of cultural and creative products are adhered to the shape, color is the most direct perception of external forms. Visual colors can directly reflect people's preference for products.

"Generally speaking, colors can directly affect the spirit just like keys. Eyes are like sounds, and hearts are just like fullstring pianos which are played by artists. They purposely play keys to arouse people's various spiritual waves and resonance"[1]. Color has many impacts on people, and the most basic one is physiological perception. Cultural and creative products add product personality through color, produce visual nerve stimulation to people, associate features with features, satisfy people's aesthetic and psychological emotional needs, and generate resonance. Color often brings a sense of spiritual pleasure, which is the externalized manifestation of the humanistic connotation in product design.

The noumenon of humanism is people. In the era of information with rapid social and economic development, the design of cultural and creative products should emphasize people-centeredness, and combine the elements of color features with the humanistic care of cultural and creative products, giving them more added value attributes. Color as a visual-leap element of cultural and creative products can provide more spiritual consumption and value identification for consumers. The color with humanistic concern in modern design is targeted at meeting the needs of the audience, which can also win the consumer's emotional identity for the product. For example, bright colors of children's products can attract children's attention, and warm-colored tourist souvenirs can bring unlimited memories to people. With the increasing attention of cultural and creative product design to color, the series of colors and sense of order are also effectively shaping the image style of the products in the development process of various products. Different colors used by products can show different feelings, which can satisfy people's profound aesthetic tastes and can transmit the emotions that the products want to express.

\section{EMOTIONAL MANIFESTATION OF COLORS IN CULTURAL AND CREATIVE PRODUCT DESIGN}

Emotional design is a design concept proposed by cognitive psychologist Donald A. Norman, the main idea of which is that a pleasant and aesthetic object is characterized by sensory appeal to impress users profoundly. The emotional connection between users and products is established due to their perception of the attractiveness of objects [2]. Emotional design is a component of the humanized design which requires adapting to people's physical and emotional demands, maximizing the way people act, know people's emotions, make people feel comfortable, and strive to bring more concern to consumers.

When choosing a cultural and creative product, color uniqueness plays a critical role. Why different people choose different colored products? Full understanding of color language and the people's emotional conversion during communication can achieve better pre-judgment of consumer behaviors by using colors.

With no specific emotional contents in colors, its emotional factors form and evolve from the human experience accumulated in the long-term labor process. With the advancement of human civilization, color and specific culture has combined into a social concept, and achieved conventional symbolic meaning [3]. The color symbolic semantics and emotional expressions in the design of cultural and creative products complement each other. The functionality of product design and the emotional expression of colors coincide with each other, which can not only explain the functional attributes of cultural and creative products, but also bring different emotions and mental feelings to people. 
To build a scientific color system, Munsell who emphasized psychological logic and visual characteristics divided color into three elements: hue, lightness, and saturation. German scientist Ostwald advocates the contrast and harmonization of colors, and organized into 24 colors through color combination. During product color design and application, the expressive power of color, the symbolism of color, the association of colors, and the emotion of color are emphasized and deepened. Therefore, the expression of color images is determined as an important part of design. Rational application of the scientific color system can interpret the characteristics of the product, express consumers' different emotional and psychological feelings, and can effectively demonstrate the beauty of cultural and creative products.

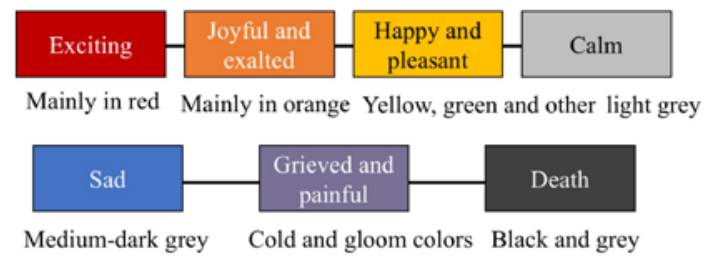

Fig. 2. Common color emotional positioning

\section{A. Warm and cold expression of colors}

"Colors can express emotions, which is an indisputable fact [4]”. For example, in order to give people a kind of icy psychological feeling, the product packaging design of summer drinks is often used in cool colors such as blue and green color combinations, which is due to the fact that the sense of temperature in color is a visual phenomenon that affects people's emotions. The change in warm and cold sense of color is a normal reaction to visual perception and an instinctive reaction to color. The orange color of the warm color system is at the top. However, the lower the sense of temperature is, the cooler the cool color and the higher the sense of temperature is. The influence of color temperature on people's emotions is manifested as passion, excitement, quietness and other rational emotions. The generation of color temperature sense of products can positively and effectively render the emotional atmosphere. Cold and warm colors also need to be properly applied according to specific products and environment. For instance, modern electronic products with scientific and technological sense are commonly used together with cold colors to embody the rationality and future feeling of the product.

\section{B. Expression of color distance and weight}

Color which can produce a sense of temperature can also bring people a sense of distance and weight. The hue, lightness and purity of the colors cam influence the sense of distance and weight. Regarding the hue, the enthusiasm of warm colors, silence and calm of cold colors make people directly feel that cold colors are more distant; at the same time, compared to the cold colors, warm colors look lighter; in terms of lightness, high brightness and low contrast combination of colors reveal soft and delicate emotional characteristics, which bring people a sense of closer distance and a lighter tone. Therefore, during color design of cultural and creative products, adopting different color combinations based on product characteristics can give different design textures to products. For instance, to express the sense of weight and time of the products, light colors can be used above the waistline. For the lower part, heavy colors can be used, which not only shows the stability of the product, but also activates the product. Regarding purity, the high purity color gives people a strong visual impact, which is more in line with the young people's feeling of individuality.. The emotional expression of high pure color combination is full of desire, active feeling, young and fashionable, and it is often used in the brand of young people. The strong color conflict sense reflects a cheerful and vivid infectivity, which can easily produce a light feeling of the product texture. Lowpurity grey does not have such a character. The emotions evoked by the colors depend on the viewer's subjective feelings. Information communication through color can stimulate consumers to react to products, and the colors can successfully interfere with consumers' psychological emotions and affect consumers.

\section{Emotional design of color matching}

Human visual system will produce different feelings, memories, associations, and preferences for color after feeling the stimulation from colors, which result in the emotional effects of color. Colors have the functions to convey information and influence emotions. Color semantics provides product with different emotions through interpretation of product features. Appropriate color sequences can bring a good visual and psychological association to the product. Different colors can create different visual stimulation. Whether the color matching is reasonable or not will affect the emotional expression of the product.

Color contrast harmony can shape the emotional color, which means colors without contrast harmony have no emotional characteristics. Color can affect emotions only in comparison. Within people's visual experience, all the colors will gather to contrast with the surroundings due to the limitation of light condition, which will affect the surrounding colors and cause more obvious differences. In this way, the characteristics can be fully developed. For example, when designing children's cultural and creative toys, high-purity, high-contrast colors can be used for tone application according to the color preference of children, supplemented with strong contrasting colors, to imperceptibly make the product eyecatchy and to attract children consumer groups. The color harmony in modern cultural and creative products based on science can be designed by effectively studying the relationship between color and human visual needs and psychological balance. Only by the use of appropriate and reasonable color configurations for the product's color contrast and blending, can the product's color and emotional expression be organically combined, so as to make the product full of humanistic atmosphere, and closer to the needs of consumers in emotional expression.

Regarding the emotional expression of cultural and creative product design, color is the most vivid and lively factor. it cannot rely merely on personal feelings and experience to achieve the consistency of the emotional expression and 
functionality of design and color. Cultural and creative product design should always be based on the "people-oriented" concept so as to fully grasp the emotions in people's hearts and to achieve the expression of color emotions in product design. How to create the emotional atmosphere with colors, and how to bring resonance with different groups of people for cultural and creative product circulation to become a means of cultural transmission is the key problem for designers to explore the emotional expression. Color is an element that directly attracts the attention of consumers. The expression of color can evoke people's positive response. However, the emotional expression process of color must be targeted, analyze the taboos of people's preferences to meet the needs of different consumers emotionally, in order to design a product that has cultural connotation and appeal and can satisfy people's emotions.

\section{CONCLUSION}

Modern cultural and creative product design is a practical commodity with aesthetic value. Through scientific color expression and reasonable color matching, we make design works rich in emotions and make products become the carriers of emotional expression. Emotional communication between the products and consumers can be achieved through exquisite design expression, which can also easily attract consumers' attention and arouse intimacy, thus contributing to consumer behavior. British famous psychologist Gregory thinks that, "color perception has extremely important significance for human beings - As the core of visual aesthetics, it profoundly affects our emotional state."[5] Color as a design language can accurately capture consumer emotions. The emotion evokes people's emotions and perceptual modeling art design, combined with new materials, new technologies, to contrast and blend with color elements such as hue, lightness, purity. Based on this, cultural and creative product design will establish the humanistic features of product design. This is the spiritual connotation of emotionalized products through design democracy, and it will also promote the development of cultural and creative products with vigorous vitality.

\section{REFERENCES}

[1] (Russia) Kandinsky. Concerning the spiritual in art, China Social Sciences Publishing House, 1987, page 35

[2] Donald ·A · Norman. The Design of Everyday Things 3: Emotional Design [M]. Translated by He Xiaomei. Beijing: China CITIC Press, 2010.

[3] Qu Min, Zhang Feng. Discussion of psychological construction of color in product design [J]. Packaging Engineering, 2005, (4): 198.

[4] Ren Yi. Analysis of Arnheim's visual perception theoretical elements [J].Time Education magazine, 2015(19): 219-219.

[5] Li Yanzu, Wang Mingzhi. Design Art Psychology [M]. Beijing: Tsinghua University Press, 2006:7.

[6] Zhao Pingyong, Design Chromatics [M], Beijing: Communication University of China, 2006.

[7] Xi Yueliang, Design Colors [M], Beijing: China Electric Power Press, 2009. 